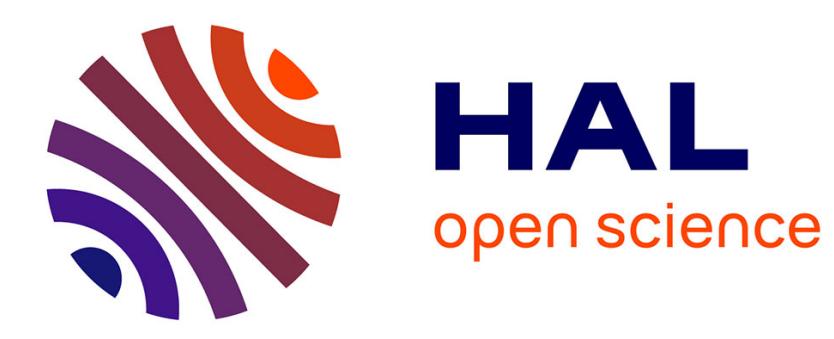

\title{
The structure of nitrogen-supersaturated ferrite produced by ball milling
}

Jochen Aufrecht, Andreas Leineweber, Eric Jan Mittemeijer, Jacques Foct

\section{To cite this version:}

Jochen Aufrecht, Andreas Leineweber, Eric Jan Mittemeijer, Jacques Foct. The structure of nitrogensupersaturated ferrite produced by ball milling. Philosophical Magazine, 2008, 88 (12), pp.1835-1855. 10.1080/14786430802322198 . hal-00513934

\section{HAL Id: hal-00513934 \\ https://hal.science/hal-00513934}

Submitted on 1 Sep 2010

HAL is a multi-disciplinary open access archive for the deposit and dissemination of scientific research documents, whether they are published or not. The documents may come from teaching and research institutions in France or abroad, or from public or private research centers.
L'archive ouverte pluridisciplinaire HAL, est destinée au dépôt et à la diffusion de documents scientifiques de niveau recherche, publiés ou non, émanant des établissements d'enseignement et de recherche français ou étrangers, des laboratoires publics ou privés. 


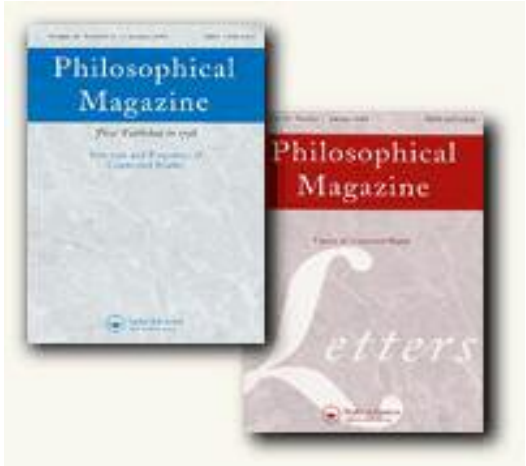

The structure of nitrogen-supersaturated ferrite produced by ball milling

\begin{tabular}{|r|l|}
\hline Journal: & Philosophical Magazine \& Philosophical Magazine Letters \\
\hline Manuscript ID: & TPHM-08-May-0145.R1 \\
\hline Journal Selection: & Philosophical Magazine \\
\hline Date Submitted by the & 30 -Jun-2008 \\
\hline Complete List of Authors: & $\begin{array}{l}\text { Aufrecht, Jochen; Max Planck Institute for Metals Research } \\
\text { Leineweber, Andreas; Max Planck Institute for Metals Research, } \\
\text { Department Mittemeijer } \\
\text { Mittemeijer, Eric Jan; Max Planck Institute for Metals Research, } \\
\text { Prof. Dr Ir. E.J. Mittemeijer } \\
\text { Foct, Jacques; Laboratoire de Métallurgie Physique et Génie des } \\
\text { Matériaux }\end{array}$ \\
\hline Keywords: & $\begin{array}{l}\text { ball-milling, lattice defects, M } \diamond \text { ssbauer spectroscopy, nanograined } \\
\text { structures, nitrides, X-ray diffraction }\end{array}$ \\
\hline Keywords (user supplied): & ball-milling, lattice defects, M ssbauer spectroscopy \\
\hline \hline
\end{tabular}

\section{(5) ScholaroNE \\ Manuscript Central}




\title{
The structure of nitrogen-supersaturated ferrite produced by ball milling
}

\author{
J. Aufrecht ${ }^{\mathrm{a}}$, A. Leineweber ${ }^{\mathrm{a}}$, J. Foct $^{\mathrm{b}}$, E.J. Mittemeijer ${ }^{\mathrm{a}}$ \\ ${ }^{a}$ Max Planck Institute for Metals Research, Heisenbergstrasse 3, D-70569 Stuttgart, Germany; ${ }^{b}$ Laboratoire de \\ Métallurgie Physique et Génie des Matériaux, UMR CNRS 8517, Université des Sciences et Technologies de \\ Lille, 59655 Villeneuve-d'Ascq Cedex, France
}

\begin{abstract}
Highly supersaturated solid solutions of nitrogen in ferrite (bcc) were produced by ball milling of various powder mixtures of $\alpha$-iron and $\varepsilon-\mathrm{Fe}_{3} \mathrm{~N}_{1.08}$. The microstructure and the crystal structure of the product phases were examined as function of nitrogen content using X-ray powder diffraction, high-resolution electron microscopy and Mössbauer spectroscopy. It was found that the grain size decreases with increasing nitrogen content. Unexpected shifts of the reflections in the X-ray powder diffraction patterns of the supersaturated $\mathrm{N}$-ferrites, depending on the $h k l$ values of the reflections and nitrogen content, were observed. It could be shown that these shifts cannot be explained by tetragonal distortion of the bcc-unit cell, but they are in accordance with the occurrence of a certain type of stacking faults on bcc-\{211\} planes. This result, together with the observation of some isolated fcc crystals (by high-resolution electron microscopy) and a drop in microstrain for high nitrogen contents, demonstrates that unconventional deformation mechanisms are operative in these materials below a certain grain size, leading to a breakdown of the classical Hall-Petch relation for mechanical strengthening.
\end{abstract}

Keywords: Ball milling,FeN alloys, X ray diffraction,Moessbauer,nanosrtucture

\section{Introduction}

Ball milling has attracted considerable attention in materials science in the last decades since it is a technique which for many systems, by a solid-to-solid route at room temperature, offers the possibility to produce non-equilibrium phases, e.g. severely distorted nanocrystalline

\footnotetext{
*Corresponding author. Email: a.leineweber@mf.mpg.de
} 
phases, extended solid solutions, disordered intermetallic phases and amorphous alloys [1-6]. In the system Fe-N, ball-milling [7-22] in particular has been frequently discussed as a possible synthetic route to produce single-phase $\alpha$ ' $-\mathrm{Fe}_{16} \mathrm{~N}_{2}$, a nitrogen-ordered martensitelike phase, which is claimed to possess unique magnetic properties [23], but has not been produced as single-phase bulk material until now. Two other metastable Fe-N phases could be produced via ball milling: (i) a solid solution of nitrogen in $\alpha$-iron with a largely extended nitrogen solubility (proposed symbol: $\alpha$ ",, [8]) up to about 16.5 at\% nitrogen [9] (thus comprising the $\mathrm{Fe}_{16} \mathrm{~N}_{2}$ composition, i.e. 11.1 at $\% \mathrm{~N}$ ), which is a multitude of the equilibrium solubility of nitrogen in $\alpha$-iron $\left(0.4\right.$ at $\%$ at $\left.592^{\circ} \mathrm{C},[24]\right)$ and (ii) an iron-rich $\varepsilon$-iron nitride in a temperature-composition window, within which the $\varepsilon$-nitride is thermodynamically unstable with respect to transformation into $\gamma^{\prime}-\mathrm{Fe}_{4} \mathrm{~N}$ or decomposition into $\gamma^{\prime}-\mathrm{Fe}_{4} \mathrm{~N}$ and $\alpha$-iron [24]. These metastable phases appear to form upon sufficiently long milling of $\alpha$-iron in the presence of a nitrogen source, independent of the type of nitrogen source whether it is solid (iron nitrides, nitrogen containing organic compounds) [7-21] or gaseous (nitrogen, ammonia) $[16,17,22]$; the type of phase formed appears to depend only on the total $\mathrm{Fe} / \mathrm{N}$ ratio of the reacting system.

Especially the solid solution of nitrogen in $\alpha$-iron with a largely extended nitrogen solubility has been subject of a number of investigations attempting to clarify the crystal-, nano- and microstructure of this phase in relation with the unusually high nitrogen solubility (up to 16.5 at\%). Usually, the solubility of nitrogen (and other interstitially dissolved atoms) is very low for bcc-type materials due to the irregular shape and limited size of the octahedral interstitial sites which gives rise to considerable local, tetragonal lattice distortion upon interstitially dissolving of nitrogen. X-ray powder diffraction (XRPD) patterns recorded from such supersaturated N-ferrites show some unexpected features: the reflection profiles tend to be asymmetric [16-19] and the lattice spacings calculated from the reflection maxima are too small in view of the nitrogen content and the known dependency $[25,26]$ of lattice parameter 
on nitrogen content for $\alpha-\mathrm{Fe}[17,20]$. As explanation for the too small lattice-parameter values, it was suggested that nitrogen segregates to defects, which are introduced in a large number by ball milling [19], or even the occurrence of an amorphous nitrogen-rich grainboundary phase was postulated [20]. The asymmetric reflection broadening was ascribed to the ferrite matrix on average being completely or partly tetragonally distorted [15-19], implying preferred occupation by nitrogen of one of the three types of octahedral interstitial sites, as in nitrogen martensite. This interpretation was rejected by other authors on the basis of Mössbauer spectroscopy and electron diffraction data [8-10]. Furthermore, in one work [7], it was noted in passing that a $h k l$-dependent reflection shift may occur with increasing nitrogen content, which effect has not been investigated further and quantified until now.

The general difficulties in obtaining an unambiguous structure model of the supersaturated solid solution of nitrogen in $\alpha$-iron, consistent with the experimental observations, is at least partly caused by the small crystallite size in combination with the high defect density which is result of the severe plastic deformation process via ball milling. This results in very broad Bragg reflections in X-ray powder-diffraction patterns, leading usually to a poor signal-to-noise ratio; also the use of optical or scanning-electron microscopy for microstructural investigations cannot provide adequate information.

The present work aims at improving the experimental data basis on the very strongly supersaturated solid solutions of $\mathrm{N}$ in $\alpha-\mathrm{Fe}$ by preparing a series of $\alpha-\mathrm{Fe}[\mathrm{N}]$ alloys of a wide range of $\mathrm{N}$ content, by ball milling mixtures of pure $\mathrm{Fe}$ and $\varepsilon-\mathrm{Fe}_{3} \mathrm{~N}_{1.08}$, which are investigated by accurate X-ray diffraction, Mössbauer spectroscopy and high-resolution transmission electron microscopy. Emphasis is laid on tracing changes in the diffraction patterns of the steady-state products with increasing nitrogen content, especially on deviations with respect to the diffraction pattern as expected for bcc-ferrite. It is checked whether these deviations can be aligned with the occurrence of overall tetragonal distortion of the ferrite. This possibility is 
disproved. Then, an alternative microstructural model, based on the occurrence of a special type of stacking faults, is proposed, which can explain the experimental results.

\section{Experimental procedure}

\subsection{Ball milling}

As starting materials, mechanical mixtures of $\alpha$-iron powder and $\varepsilon$-iron nitride powder were used. The iron powder (Alfa Aesar) had a purity of $99.9 \mathrm{wt} \%$ with respect to the metal base and a purity of $99.5 \mathrm{wt} \%$ considering also non-metallic impurities, the particle size was of less than $10 \mu \mathrm{m}$. The $\varepsilon$-iron nitride powder was produced by gas nitriding of iron powder $(3 \times 36 \mathrm{~h}$ at $510^{\circ} \mathrm{C}$ in an ammonia/hydrogen atmosphere, applying a technical nitriding furnace (C. Gommann KG, Remscheid, D, see also [27]). The $\varepsilon$-iron nitride powder had a final nitrogen content of $26.5 \mathrm{at} \%$. To prevent oxidation, the powders were stored in an argon-filled glove box. The iron and $\varepsilon$-iron nitride powders were weighted-in in specified weight ratios to establish a desired total nitrogen content in the powder mixtures and were mingled in a mortar to realize a uniform initial intermixture. The resulting powder mixtures were filled into a stainless steel vessel for milling together with stainless-steel milling balls of $10 \mathrm{~mm}$ diameter, also in the argon-filled glove box to assure an inert atmosphere inside the vessel. The use of about $7.2 \mathrm{~g}$ of powder mixture together with 35 milling balls resulted in a constant powder-toballs weight ratio of 1:20 for all experiments. The vessel was afterwards sealed by an o-ring and additionally by parafilm. The powders were milled in a "Fritsch Pulverisette 6" planetary ball mill at a rotational speed of $500 \mathrm{rpm}$ for $40 \mathrm{~h}$ (effective milling time). Every 30 minutes, the milling process was interrupted for 20 minutes to minimize the temperature raise during milling. After each interruption, the direction of rotation was reversed.

\subsection{X-ray powder diffraction (XRPD)}


For one powder mixture (sample A5, see section 3 and table 2), the alloying process during ball milling was traced as a function of milling time by XRPD measurements using a Guinier camera "Enraf Nonius FR 552" applying Mo-K $\alpha_{1}$ radiation $(\lambda=0.70926 \AA)$. To this end, a few mg of sample material were removed from the vessel after certain milling times in the argonfilled glove box. The amount of removed material was small enough to ensure that the ball-topowder weight ratio was not changed significantly.

The steady-state products as obtained after $40 \mathrm{~h}$ of ball milling in all experiments were examined using an X'PERT Multi-Purpose-Diffractometer in $\theta-\theta$-Bragg-Brentano geometry, employing Co-K $\alpha$ radiation $\left(\lambda_{\alpha 1}=1.78897 \AA, \lambda_{\alpha 2}=1.79258 \AA\right)$ and using a monochromator in the diffracted beam. For this purpose the powders were suspended in isopropanol and sedimented on a (510)-cut Si crystal plate (wafer) using a supporting brass ring during evaporation of the liquid.

The thus recorded diffraction patterns were analysed using the program TOPAS [28]. An instrumental-profile function was determined for the chosen diffractometer setting using a $\mathrm{LaB}_{6}$ powder (NIST standard reference material, SRM660a) employing the fundamental parameters approach [29]; some parameters pertaining to certain instrumental-line profile contributions like the wavelength-distribution function were allowed to be refined in the fitting of the $\mathrm{LaB}_{6}$ reflections. The instrumental profile thus obtained was convoluted with a split pseudo-Voigt function for each single bcc-type reflection, using the programming language available in the Launch Mode of TOPAS. By least-squares-fitting to the reflections recorded from the ball-milled powders, the parameters peak maximum $\left(2 \theta_{\max }\right)$, full width at half maximum (FHWM), asymmetry, intensity and mixing parameter of the pseudo-Voigt functions were extracted for each single reflection (data in sections $3.2-3.4$ ).

\subsection{Chemical Analysis}


The nitrogen content and the extent of oxygen contamination of the final products were determined using carrier-gas hot extraction (ELTRA ONH 2000).

\subsection{Mössbauer spectroscopy}

Spectra were obtained at room temperature in transmission geometry with a Wissel driver working in the constant acceleration mode in the velocity interval $\left(-8,+8 \mathrm{~mm} \mathrm{~s}^{-1}\right)$. The ${ }^{57} \mathrm{Co}$ atoms of the $50 \mathrm{mC}$ source are dissolved in a rhodium matrix.

\subsection{Transmission electron microscopy}

For high-resolution transmission electron microscopy (HRTEM) examinations, the powders were mixed with an epoxy resin and put between two silicon discs, which are strengthened by aluminum bars on top and on bottom. After hardening of the epoxy resin, cross-sectional slices were cut from the package, which were dimpled and ion-thinned to achieve an electron transparent sample thickness. The samples were examined with a JEOL-ARM 1250 transmission electron microscope applying an electron acceleration voltage of $1250 \mathrm{kV}$.

\section{Experimental results}

\subsection{Chemical composition of the as-milled samples}

Chemical analysis showed that no loss of nitrogen occurred during ball milling, see Table 2 . The slight increase in nitrogen content detected for most of the samples (compare Table 2 and Table 1) is attributed to uptake of nitrogen from the atmosphere, which is unavoidable in the ball milling experiment, despite the measures taken to prevent contamination by atmospheric gases (cf. section 2.1). The same holds for the increase in oxygen content, which is expected to lead to formation of oxides, which however were not detected by X-ray diffraction. Hence, as the nitrogen content changed slightly during milling, the final (steady-state) $\mathrm{N}$ content in the as-milled state, as determined by chemical analysis, will be referred to henceforth. 
\{Place Tables 1 and 2 about here\}

\subsection{Phase analysis}

The evolution of the mechanical alloying process was traced for sample A5 as function of milling time using XRPD (Fig. 1). Already during the initial stages of milling, a strong broadening of the originally $\alpha-\mathrm{Fe}$ and $\varepsilon$-reflections is induced, obviously caused by both severe plastic deformation and the associated reduction in crystallite size (cf. section 3.3). Also compositional variations due to nitrogen redistribution processes will contribute to the diffraction-line broadening. The reflections of the $\varepsilon$-nitride are no more detectable after several hours of milling. Obviously, under the mechanical activation by ball milling, the $\varepsilon-$ nitride reacts with the $\alpha$-iron to a supersaturated solid solution of nitrogen in $\alpha$-iron, as there is no loss of nitrogen to the atmosphere in the milling vessel (Table 2).

\{Place Fig. 1 about here\}

However, the non-detectability by XRPD of a given phase after extended ball milling does not constitute an unambiguous proof of its absence, because, due to the extreme diffraction-line broadening, the reflections of severely deformed material can become indistinguishable from the background signal [1]. In order to resolve this ambiguity, an additional diffraction pattern (Fig. 2) was recorded from a mechanical mixture of $40 \mathrm{~h}$ separately milled pure $\alpha$-iron and a $40 \mathrm{~h}$ separately milled pure $\varepsilon$-iron nitride powder, in the same weight ratio as for the initial powder pertaining to Fig. 1 (i.e. milled in the mixed fashion). In this case, the reflections of the $\varepsilon$-iron nitride can be discerned clearly. Hence, upon ball milling a mixture of $\alpha$-iron powder together with $\varepsilon$-iron nitride powder, the nitride phase dissolves, and an apparently supersaturated solid solution of nitrogen in $\alpha$-iron remains. 
After $40 \mathrm{~h}$ of milling a steady state with respect to phase composition (single-phase supersaturated $\mathrm{N}$-ferrite) as well as microstructure (no further change of diffraction-line broadening) is reached. Results analogous to those presented here for sample A5 were obtained for all milling experiments performed with all samples with different weight ratios of $\alpha$-iron and $\varepsilon$-iron nitride; i.e. up to a total nitrogen content of 15.6 at $\%$ nitrogen in the steadystate product (Table 2, Fig. 3). For samples with higher nitrogen content, $\varepsilon$-iron nitride was detected additionally to the supersaturated ferrite. It strikes that the upper limit of about 16 at $\%$ nitrogen for supersaturated $\mathrm{N}$-ferrite is about equal to the lower limit of nitrogen content for $\varepsilon$-iron nitride at elevated temperatures (see phase diagram in Ref. [24]).

\{Place Fig. 2 and 3 about here\}

\subsection{Microstructural imperfection}

From the broadening of the reflections of the N-ferrites (additional to the instrumental resolution), reaching a steady state after $40 \mathrm{~h}$ of milling, information on the microstructure as function of the total nitrogen content can be obtained. One method suitable to characterize and quantify the crystallite size and microstrains is the method proposed by Williamson and Hall $[4,30]$. If the broadening is solely caused by variations in d-spacing (lattice distortions, dislocations, compositional variations), the effective mean microstrain, $e$ (to be interpreted as a measure for the standard deviation of the microstrain distribution [31]), is given by the integral breadth of the reflection with the Laue indices $h k l$

$$
\beta_{e, h k l}=4 e \tan \theta_{\max , h k l},
$$

where $\theta_{\max , h k l}$ is the peak position (e.g. peak-maximum position). If the broadening originates solely from a reduction of the size of coherently diffracting domains (reduction of crystallite size, stacking faults, twins) the integral breadth of the reflection $h k l$ is given by 


$$
\beta_{D, h k l}=\frac{\lambda}{D \cos \theta_{\max , h k l}},
$$

where $D$ is the mean size of the coherently diffracting domains and $\lambda$ is the wavelength. According to the Williamson-Hall analysis, both contributions to the total broadening add linearly (which holds exactly if the line-broadening contributions are of Lorentzian shape) and one obtains for the total physical (size and strain) broadening (integral breadth $\beta_{h k l}$ ):

$$
\frac{\beta_{h k l} \cos \theta_{\max , h k l}}{\lambda}=\frac{1}{D}+\frac{4 e \sin \theta_{\max , h k l}}{\lambda} .
$$

Plotting $\frac{\beta_{h k l} \cos \theta_{\text {max }, h k l}}{\lambda}$ vs. $\frac{4 \sin \theta_{\text {max }, h k l}}{\lambda}$ should yield a straight line with a slope providing a value for $e$ and an ordinate intercept providing a value for $1 / D$ (Figs. 4, 5a/b). The values for $1 / D$ thus obtained for the $\mathrm{N}$-ferrites (using the 110, 211 and 220 reflections and leaving out the weak 200 reflection) increase largely linearly with total $\mathrm{N}$ content, while $e$ exhibits a nonlinear dependence on nitrogen content: an increase up to medium nitrogen content, followed by a decrease in microstrain broadening to virtually nil.

\{Place Figs. 4 and 5 about here\}

\subsection{Crystal structure analysis}

An increase of the amount of interstitially dissolved nitrogen in $\alpha$-iron leads to an increase of the lattice parameter of $\alpha$-iron. The relation between nitrogen content and lattice parameter has been well investigated for solid solutions of nitrogen in $\alpha$-iron within the small equilibrium homogeneity range $[25,26]$. It has also been shown that the increase in volume per iron atom with nitrogen content is given by the same linear dependence for $\alpha^{\prime}$-nitrogen martensite and $\varepsilon$-iron nitrides (for nitrogen contents less than 33 at.\%) [32]. It is questioned whether these dependencies also hold for ferrites of large nitrogen supersaturation as produced by ball milling. 
In the present investigation, the positions of the maxima of four reflections $(110,200$, 211 and 220) were determined and the corresponding d-spacings were calculated (Fig. 6a). These values obtained for $d_{h k l}$ as function of $h k l$ are clearly incompatible with a single cubic lattice parameter $a$ : $h k l$-dependent lattice parameters occur, which can be described by

$$
a_{h k l}=d_{h k l} \sqrt{h^{2}+k^{2}+l^{2}}
$$

where $a_{h k l}$ can be called "apparent lattice parameter", similar to an approach in an other case where anisotropic reflection shifts occurred [33]. With increasing nitrogen content $a_{110}, a_{211}$, $a_{220}$ increase to different degrees (i.e. the reflection positions shift to lower values of $2 \theta$ ), whereas $a_{200}$ decreases (i.e. the reflection position shifts to higher values of $2 \theta$ ). In case of initially pure iron $(0.77$ at $\% \mathrm{~N})$, the effect is very small, but detectable. A possible interpretation of the occurrence of the apparent lattice parameter and its dependencies on $2 \theta$ and nitrogen content is given in section 4 .

\{Place Fig. 6 about here\}

Mössbauer spectra of samples A2, A5 and A6 resemble closely those published for a similar case [9] and clearly differ from Mössbauer spectra recorded for Fe-N martensite $\left(\alpha^{\prime}\right)$ [34], as shown in Fig. 7. This difference of the ball-milling product, nitrogen ferrite, and nitrogen martensite is emphasized by the results of ageing (at temperatures between 100 and $\left.200^{\circ} \mathrm{C}\right)$ : In case of $\alpha$, the ordered $\alpha^{\prime \prime}-\mathrm{Fe}_{16} \mathrm{~N}_{2}$ nitride phase appeared, whereas for supersaturated nitrogen ferrite, the $\gamma^{\prime}-\mathrm{Fe}_{4} \mathrm{~N}$ phase appears [35].

Data concerning the distribution of $\mathrm{N}$ interstitials, in terms of the iron environments, in the ball-milled supersaturated nitrogen ferrite were obtained by numerical fitting of the Mössbauer spectra on the basis of least-squares fitting adopting a Lorentzian peak-shape function corresponding to absorption peaks as obtained for thin absorber conditions. 
Statistically acceptable results were obtained on the basis of 7 sets of 6 peaks corresponding to 7 different magnetic states of iron atoms and with an additional single peak close to $0 \mathrm{~mm}$ $\mathrm{s}^{-1}$ velocity corresponding to the clearly paramagnetic or super-paramagnetic peak revealed by the experimental spectra. Similar results were obtained for samples A2 to A6; results for sample A5 are shown in Fig. 7.

\{Place Fig. 7 and Table 3 about here\}

Different iron environments correspond to different domains of hyperfine parameters. In agreement with Ref. [9], distinction of iron environments can be based mainly on the hyperfine magnetic field $H$. Three domains $\Delta_{i}$ of $H$ defined by $32-36 \mathrm{~T}, 27-31 \mathrm{~T}$ and $23-$ $26 \mathrm{~T}$ have thus been distinguished and identified as due to iron atoms with $0,1,2 \mathrm{~N}$ interstitial neighbours $\mathrm{Fe}_{0}, \mathrm{Fe}_{1}, \mathrm{Fe}_{2}$; their relative abundances, $P_{i}$, have been indicated in Table 3 .

In contrast with the environments $\mathrm{Fe}_{0}, \mathrm{Fe}_{1}, \mathrm{Fe}_{2}$, for which a reasonable interpretation of the interstitial neighbourhood is possible, interpretation of the iron environment corresponding to the central single peak is uncertain. This central single peak most likely is caused by small domains of paramagnetic phases such as austenite (the isomer shift of -0.05 $\mathrm{mm} \mathrm{s}^{-1}$ is comparable with the value obtained for the most symmetrical site of FeN austenite, $-0.1 \mathrm{~mm} \mathrm{~s}^{-1}$ ) or zones close to lattice defects for which some nitrogen segregation may have taken place, therefore the corresponding mean environment is referred to as $\mathrm{Fe}_{n}$ with $n=3 \pm$ 1.

Due to the six-fold coordination of $\mathrm{N}$ by Fe in an octahedral interstitial site of the bccFe lattice, the following relation between the relative abundances $P_{i}$ of the environments $\mathrm{Fe}_{i}$ $(0 \leq i \leq 6)$ and the nitrogen/iron atomic ratio $y$ of the supersaturated ferrites holds:

$$
y=1 / 6 \cdot \sum_{i} P_{i} \cdot i
$$


Taking the data from Table 3, it thus follows $y=0.112 \pm 0.01$, i.e. 10.1 at $\%$ nitrogen, which agrees reasonably well with the $\mathrm{N}$ content of sample A5 as given by the $\alpha-\mathrm{Fe}$ and $\varepsilon-\mathrm{Fe}_{3} \mathrm{~N}_{1.08}$ powder fractions and proved by chemical analysis (Table 2). A comparison of the Mössbauer site abundances with those corresponding to a binomial distribution (see Table 3) shows that the occupation of interstitial sites by $\mathrm{N}$ atoms in the supersaturated ferrite does not occur completely disorderedly.

High-resolution transmission-electron microscopy of samples A1 (nearly pure iron; 0.77 at $\%$ nitrogen) and $\mathrm{A} 4$ (10.8 at $\%$ nitrogen) confirms a main result of the line-broadening analysis (section 3.3): the crystallite size decreases with increasing nitrogen content. This can be directly concluded from the high-resolution images and the selected-area diffraction (SAD) patterns, where for both samples an electron-diffraction pattern was taken from an area of the same size (Fig. 8). In case of the pure iron sample single spots corresponding to several individual crystals are discernible, whereas in case of the nitrogen-rich sample, reflection spots from a much larger number of very small, randomly oriented crystallites are superimposed and give rise to the formation of diffraction rings.

The analysis of the high resolution images is difficult due to (i) the small crystallite size, which frequently leads to overlapping of crystallites of different orientations in the viewing direction, and (ii) the severe lattice distortions.

In one case, for the nitrogen-rich sample, a specific orientation relationship between adjacent crystallites could be observed: $\{1 \overline{1} 0\}_{\text {bcc1 }} \|\{110\}_{\text {bcc } 2}$ and $<111>_{\text {bcc } 1} \|<001>_{\text {bcc } 2}$, see Fig. 9. Also, as an unfrequent observation, a crystallite adjacent to grain 2 is visible in Fig. 9, which obviously has a fcc structure with the orientation relationship: $\{110\}_{\text {bcc } 2} \|\{1 \overline{1} 1\}_{\text {fcc }}$ and $<001>_{\text {bcc } 2} \|<110>_{\text {fcc }}$.

\{Place Figs. 8 and 9 about here\} 


\section{Interpretation of results}

\subsection{Steady state for crystallite size and microstrain as function of nitrogen content}

The crystallite size upon ball milling is determined in general by two competing processes: formation of grain boundaries by breakage and rewelding of crystallites or dislocation rearrangement on the one side and dynamic recrystallization on the other side [36]. The results from the Williamson-Hall plots (Figs. 5a,b) and the HRTEM investigations (Figs. 8, 9) show that the steady-state (ferrite) crystallite size after $40 \mathrm{~h}$ of ball milling decreases with increasing nitrogen content of the ferrite. This can be explained as follows. The strong decrease of the eventual mean value of $D$ with increasing nitrogen content indicates that nitrogen stabilizes the grain boundaries and thereby hinders dynamic recrystallization. Additionally, segregation of nitrogen at defects in the bulk ffootnote: Segregation of interstitial atoms to one- and/or two-dimensional crystal defects contributes to an apparent enhancement of the solubility of nitrogen in $\alpha$-iron [37] or in ferritic Fe-Me ( $\mathrm{Me}=$ e.g. $\mathrm{Cr}$, Mo, V, Ti) systems [38], but to a very much smaller extent as in case of the present supersaturated $\mathrm{N}$-ferrites produced by ball milling\} (as dislocations and, in particular (see section 4.2.3), stacking faults) restricts dislocation mobility (solid-solution hardening) and thereby increases the brittleness, promoting breakage of the crystallites.

The variation of microstrain $e$ with nitrogen concentration, Fig $5 \mathrm{~b}$, may be ascribed to a variation of the yield limit (or hardness). The increase in yield limit, and thus consequently, an increase of the observed value of microstrain $e$, with increasing nitrogen content, here up to about 7 at $\% \mathrm{~N}$, is caused by (i) nitrogen-induced solid solution hardening and (ii) increased grain-boundary density (cf. Hall-Petch relation). For higher nitrogen contents (here, beyond about 7 at $\%$ ), the grain size is reduced further (Fig. 5a). Below a critical value of the grain size a breakdown of the Hall-Petch relation can occur: For such small grain sizes, a decrease in yield limit with decreasing grain size has been reported for many metallic systems (so-called inverse Hall-Petch relation) [39]. This effect is attributed to 
stress relaxation mechanisms specific for nanosized microstructures which become active and replace dislocation glide as predominant mechanism for plastic deformation: grain-boundary diffusion, grain-boundary sliding, nano-twinning, formation of intrinsic and extrinsic stacking faults $[40,46,47]$. Hence for a grain size smaller than a critical value, here about $10 \mathrm{~nm}$, a decrease of microstrain $e$ can occur.

\subsection{Occurrence of fcc-type crystallites and special orientation relationships}

The observation of the orientation relationship $\{1 \overline{1} 0\}_{\text {bccl }} \|\{110\}_{\text {bcc } 2}$ and $<111>_{\text {bcc } 1} \|<001>_{\text {bcc } 2}$, and the occurrence of a fcc structure with the orientation relationship $\{110\}_{\text {bcc } 2} \|\{1 \overline{1} 1\}_{\text {fcc }}$ and $<001>_{\text {bcc } 2} \|<110>_{\text {fcc }}$, (see Fig. 9; section 3.4) parallels observations made previously for the Fe-C system (pearlitic steel) after severe deformation by highpressure torsion $[41,42]$. Such data can be an indication of an unconventional deformation mechanism operating in nanocrystalline iron-based alloys containing interstitial solute atoms. Molecular dynamics simulations [43] for crack-tip regions in nanocrystalline (pure) iron have shown that upon loading the local formation of a transitional fec phase is possible by a shear process along the bcc- $\{110\}$ planes, which is basically a bcc-like to fcc structure transformation. Upon further shearing, the transitional fcc phase is transformed back to bcc. The orientation relationship as predicted by these simulations agrees with the one observed in the here discussed HRTEM image (Fig. 9). The presence of nitrogen or carbon stabilizes the austenite, fcc phase, which promotes the occurrence of the above indicated deformation mechanism.

\subsection{Crystallography of supersaturated $N$-ferrite}

The shifts of the reflection maxima of the supersaturated $\mathrm{N}$-ferrites as functions of $h k l$ and nitrogen content are the most striking observations of this work. Two possible explanations 
for these phenomena will be discussed here, (i) tetragonal distortion of the bcc unit cell of the supersaturated $\mathrm{N}$-ferrite and (ii) the presence of a certain type of stacking faults.

\subsubsection{Tetragonal distortion of the ferrite, bcc unit cell}

The occurrence of a tetragonal distortion of the bcc unit cell was proposed previously as a possible explanation for the observed asymmetric nature of the line broadening [15-19] (a systematic $h k l$-dependence of the shifts of the reflection maxima was not reported in these works). This tetragonal distortion would be realized by preferential occupation by nitrogen of only one type (of three types) of octahedral interstices; i.e. Zener ordering. However, this ordering process is unlikely already because ball milling generally promotes disorder [1]. The effect can be abandoned in particular on the basis of the following evaluation.

Tetragonal distortion leads to splitting of the bcc reflections into sub-reflections with a specific intensity ratio (only reflections with $|h|=|k|=|l|$ are not affected by tetragonal distortion). For all-different $|h|,|k|,|l|$ there is a splitting into three sub-reflections ("triplets") with an intensity ration of $1: 1: 1$, in case of $|h|=|k| \neq|l|$ or $|h| \neq|k|=|l|$, the original bcc reflection splits into two bct (body-centered tetragonal) subreflections ("doublets") with an intensity ratio of 2:1 (this case would pertain to the four bec type reflections considered in this work). When reflection broadening is very pronounced, as in case of the supersaturated Nferrites produced by ball milling, such sub-reflections may overlap, leading to asymmetric pseudo-bcc reflections, whose maxima are shifted with respect to the expected values for an undistorted bec structure.

To check the validity of the proposal of tetragonal distortion it is reasonable to analyse the measured patterns with reflection groups, each group corresponding to one bcc reflection, representing the split-up sub-reflections ("doublets") formed by tetragonal distortion. In case of the four reflections analyzed in this work, pairs of pseudo-Voigt functions were fitted to each of the reflection groups taking into account the instrumental broadening, on the basis of 
the "fundamental parameters" determined from the $\mathrm{LaB}_{6}$ measurements (section 2.2). The reflection maxima for each of the sub-reflections in the reflection groups were determined by fitting values for the lattice parameters $a$ and $c$, determined by fitting jointly to all reflections. The peak-profile parameters, full width at half maximum (FHWM) and mixing parameter (the asymmetry was set to nil), were fitted individually for each sub-reflection. The integral intensity ratios were fixed for every pair of sub-reflections (= "reflection group") to be 2:1 (see above), whereas the total (i.e. integral) intensities of the tetragonal doublets were refined independently.

The results of this refinement procedure for sample A4 are shown in Fig. 10. It is evident that the measured diffraction pattern cannot be described on the basis of the fitting results: Neither, the shape of the bcc-110 reflection nor the position of the bcc-211-reflection can be modeled adequately with the concept of tetragonal lattice distortion. Moreover, the bcc-200 reflection could only be described on this basis with physically unreasonably large FHWM values for the bct-002 sub-reflection and the bct-112 sub reflection, see Table 4.

Hence, tetragonal lattice distortion does not provide a consistent explanation of the individual peak-maximum shifts and peak shapes. Former suggestions of tetragonal distortion [15-19], on the basis of the line broadening of a single reflection, are untenable.

\{Place Fig 10 and Table 4 about here\}

\subsubsection{Stacking faults including spacing faults on bcc $\{211\}$-planes}

Based on a theoretical framework by Warren [44], Wagner, Tetelmann and Otte calculated the effect of stacking faults on $\{211\}$-planes in bcc crystals [45] on the positions of reflection maxima in (X-ray) powder-diffraction patterns. The most important aspect of this model is the recognition that the introduction of such a stacking fault, which is characterized by a displacement of $a / 3<1 \overline{1} \overline{1}>$ parallel to the $\{211\}$-stacking fault plane, is associated with an 
increase in layer spacing at and perpendicular to the stacking fault plane, adopting a hard spheres model for the Fe atoms (this contrasts with stacking faults on $\{111\} /\{001\}$ closepacked planes in fcc/hcp-type structures, respectively, which stacking faults are not associated with lattice-spacing changes). This "spacing fault", which accompanies the stacking fault, involves the occurrence of specific $h k l$-dependent shifts of reflection maxima.

The model predicts that the positions $\left(2 \theta_{h k l}\right)$ of the reflection maxima are shifted by the presence of the above described type of layer fault by an amount

$$
\Delta 2 \theta_{h k l}=-2 J^{\prime}{ }_{h k l} \alpha \varepsilon \tan \theta_{0, h k l},
$$

where $\theta_{0, h k l}$ is the diffraction angle calculated for the cubic lattice parameter $a_{0}$, and where $\alpha$ is the stacking fault probability and $\varepsilon$ is the local change in layer spacing between two adjacent $\{211\}$-layers comprising a stacking fault and is given by

$$
\varepsilon=\frac{d_{S F, 211}-d_{0,211}}{d_{0,211}},
$$

where $d_{\mathrm{SF}}$ is the strained $\{211\}$-lattice plane spacing at the stacking fault and $d_{0}$ is the regular $\{211\}$-lattice plane spacing (calculated from $a_{0}$, see above). $J^{\prime}{ }_{h k l}$ is a constant which is characteristic for each $h k l$ and takes into account that reflections in a powder-diffraction pattern can be composed of different sub-reflections corresponding to permutation of $h k l$ indices and which are inequivalent with respect to the type of stacking/spacing faulting. Values for $J_{h k l}^{\prime}$ are given in Table 5. The "apparent" lattice parameter (cf. Eq. (4)) can be derived from $2 \theta_{h k l}=2 \theta_{0, h k l}+\Delta 2 \theta_{h k l}$ using Bragg's law and Eq. (6). It follows

$$
a_{h k l}=a_{0}\left(1+J^{\prime}{ }_{h k l} \alpha \varepsilon\right)
$$

Comparing the values for $J_{h k l}$, which determine the deviation of the apparent lattice parameters from the lattice parameter $a_{0}$, with the trends for the experimentally determined apparent lattice parameters of the supersaturated N-ferrites, shows that the effect discussed can at least qualitively explain the observations (Fig. 6a). 
\{Place Table 5 about here\}

Values for $a_{0}$ and $\alpha \varepsilon$ were determined by fitting Eq. (8) to the apparent lattice parameters as observed for the supersaturated N-ferrites: the sum of the squared deviations between experimentally observed apparent lattice-parameter values and the apparent latticeparameter values calculated from Eq. (8) was minimized by adopting $a_{0}$ and $\alpha \varepsilon$ as fit parameters.

Comparison of the experimentally determined data (Fig. 6a) and the best fits for the various nitrogen contents (Fig. 6b) shows that some deviations occur, which are mainly caused by an apparent lattice parameter deduced from the 110 reflection that is larger than that deduced from the 220 reflection, which is impossible according to the model used here.

The resulting values for the two fit parameters $a_{0}$ and $\alpha \varepsilon$ are shown in Fig. 11. Their physical plausibility can be discussed as follows: The lattice parameter $a_{0}$, for the unfaulted cubic ferrite, increases with increasing nitrogen content, but not as strongly as expected by extrapolation the relations given in $[25,26]$ for ferrite with nitrogen contents up to 0.2 at $\%$. This could be due to the segregation of nitrogen at lattice defects, where less dilation is required to accommodate the dissolved nitrogen (tensile strained region at dislocation line; octahedral site at stacking fault larger than in the bulk (see below)).

\{Place Fig 11 about here\}

The octahedral interstitial sites at the stacking faults are larger than those in the bulk: the distance between the interstitial site and the nearest neighbouring Fe atoms is by $19 \%$ larger at a stacking fault; cf. Fig. 12. Hence incorporation of interstitial nitrogen atoms at these octahedral interstices leads to less elastic energy than at octahedral interstices in the bulk. For realization of ideal octahedral symmetry some relaxation of atoms (atomic 
shuffling) is needed within the faulted $\{211\}$-plane, which is likely to occur (see also Fig. 12). The existence of this type of stacking faults could not be proven by HRTEM imaging. Best visibility is expected in grains with $<211>$ parallel to the incident electron beam, i.e. then the stacking fault is imaged edge-on, but only for two of the six equivalent $<211>$ directions, which orientations practically did not occur in the investigated foils.

\{Place Fig 12 about here\}

The parameter $\alpha \varepsilon$ determines the extent of the anisotropic hkl reflection shift (Eq. (8)). Its observed increase with increasing nitrogen content (Fig. 11) could be attributed to an increase of $\alpha$, the stacking fault density (probability), and/or to an increase of $\varepsilon$, the increase in layer spacing at the stacking fault. It may be suggested that stacking faults in the present samples are stabilized by the presence of dissolved nitrogen, as discussed above, which can explain the increase of $\alpha \varepsilon$ with nitrogen content. An alternative or complementary interpretation of the increase in stacking fault density with increasing nitrogen content could be given recognizing the decrease of crystallite size with increasing nitrogen content (Fig. 5a, section 4.1): Planar faulting (introduction of stacking faults and/or twins) can replace glide of perfect dislocations as predominant plastic deformation mode in nanocrystalline materials, which has been observed e.g. for nanocrystalline aluminum, whereas planar faults have not been observed in coarse grained aluminum upon plastic deformation [46,47]. Further, twinning upon plastic deformation has been observed in different nanocrystalline fcc metals, which yields no net macroscopic strain, but is supposed to assist plastic deformation by favourable reorientation of grains [48].

If the atoms of the bcc crystal would be hard spheres, $\varepsilon$ can be estimated to be 0.06 [45]. Adopting this value of $\varepsilon, \alpha$ would be 0.75 in case of the sample of highest nitrogen content in this study, which is unrealistic as the resulting crystal structure would no longer 
correspond to a (distorted) overall bcc-crystal structure. Hence, it appears that also $\varepsilon$ increases considerably with nitrogen content, e.g. to 0.2 , which would lead to realistic $\alpha$ values. Such increase of $\varepsilon$ is compatible, indeed, with the above suggested nitrogen segregation at the stacking faults.

\section{Conclusions}

Extremely supersaturated $\mathrm{N}$-ferrites, with nitrogen contents up to $15.6 \mathrm{at} \%$, can be produced by ball milling mixtures of pure iron powder and $\varepsilon$-iron nitride powder. The nitrogen content has a strong influence on the values for crystallite size and microstrain attained in the steady state (after $40 \mathrm{~h}$ of ball milling). A small fraction of fcc-like crystallites occurs for the ballmilled iron-nitrogen alloys.

The crystallite size decreases with increasing nitrogen content, due to the stabilization of grain boundaries by nitrogen segregation, thereby hindering dynamic recrystallization, and a more brittle nature of the material promoting fracture of the crystallites.

The increase in microstrain broadening up to about 7 at $\%$ nitrogen is due to the increase in yield limit caused by the nitrogen solute atoms and an increase of grain-boundary density. Below a critical value of grain size (occurring for nitrogen content larger than about 7 at $\%$ ) a decrease of microstrain is due to a decrease of yield limit caused by a replacement of dislocation glide as predominant mechanism for plastic deformation by alternative mechanisms.

The bcc reflections in the XRPD patterns show characteristic $h k l$-dependent shifts which increase with increasing nitrogen content. Interpretation of these reflection shifts as caused by a tetragonal lattice distortion, as proposed previously, is incompatible with the experimental results obtained for a series of $h k l$ reflections as well as with Mössbauer spectra. The shifts can consistently be ascribed to the occurrence of stacking faults on bcc- $\{211\}$ planes, in association with spacing faults. 
The occurrence of a stacking-fault density increasing with increasing nitrogen content (i.e. with decreasing crystallite size) and the non-monotonous variation of microstrain with increasing nitrogen content (i.e. with decreasing crystallite size), exhibiting a maximum value at a specific grain size, indicates the breakdown of the classical Hall-Petch relation for describing the mechanical strength of the nanosized microstructure resulting from ball milling.

\section{Acknowledgements}

The Authors whish to thank Dr. F. Phillipp and Ms. M. Kelsch from the Stuttgart Center for Electron Microscopy (STEM) at the Max-Planck Institute for Metals Research for TEM analysis

\section{References}

[1] C. Suryanarayana, Prog. Mater. Sci. 46 (2001), p.1.

[2] E. Gaffet and G. Le Caer, Mechanical Processing for Nanomaterials, in Encyclopedia of Nanoscience and Nanotechnology, Vol. 5, H. S. Nalwa (ed.), American Scientific Publishers, Stevenson Ranch, CA, 2004, p.91.

[3] I. Lucks, P. Lamparter and E.J. Mittemeijer, Acta Mater. 49 (2001) p.2419.

[4] I. Lucks, P. Lamparter and E.J. Mittemeijer: J. Appl. Crystallogr. 37 (2004) p.300.

[5] P. Lamparter and E.J. Mittemeijer: Int. J. Mater. Res. 98 (2007) p.485.

[6] C.C. Koch, Nanostruct. Mater. 9 (1997) p.13.

[7] T. Koyano, T. Takizawa, T. Fukunaga and U. Mizutani, Jpn. J. Appl. Phys. 32 (1993) p.1524.

[8] J.Foct and R.S. de Figueiredo, Nanostruct. Mater. 4 (1994) p.685.

[9] R.S. de Figueiredo and J. Foct, Mater. Sci. Forum 179-181 (1995) p.219.

[10] J. Foct, R.S. de Figueiredo, O. Richard and J.P. Morniroli, Mater. Sci. Forum 225-227 (1996) p.409.

[11] H. Xu, K.H. He and L.Z. Cheng, J. Magn. Magn. Mater. 174 (1997) p.316.

[12] T. Saito, J. Appl. Phys. 87 (2000) p.6514. 
[13] K. Sumiyama, H. Onodera, K. Suzuki, S. Ono, K.J. Kim, K. Gemma and Y. Nishi, J. Alloy Compd. 282 (1999) p.158.

[14] T. Yamagutchi and H. Saihata, J. Magn. Magn. Mater. 254-255 (2003) p.20.

[15] K.J. Kim, K. Sumiyama, H. Onodera and K. Suzuki, J. Alloy Compd. 203 (1994) p.196.

[16] J.C. Rawers, D. Govier and D. Cook, Scr. Metall. Mater. 32 (1995) p.1319.

[17] J.C. Rawers, D. Govier and R.Doan, Mater. Sci. Eng. A 220 (1996) p.162.

[18] A. Munitz, G. Kimmel, J.C. Rawers and R.J. Fields, Nanostruct. Mater. 8 (1997) p.867.

[19] J.C. Rawers, D. Cook and T. Kim, Phil. Mag. A 78 (1998) p.965.

[20] J.M.D. Coey and K.O. O’Donnell, Mater. Sci. Forum, 179-181 (1995) p.513.

[21] G.M. Wang, S.J. Campbell and W.A. Kaczmarek, Mater. Sci. Eng. A 226 (1997) p.80.

[22] Y. Chen, J.S. Williams and G.M. Wang, J.Appl. Phys. 79 (1996) p.3956.

[23] K.H. Jack, Proc. R. Soc. Lon. A 208 (1951) p.216.

[24] H.A. Wriedt, N.A. Gokcen and R.H. Nafziger, Bull. Alloy Phase Diagr. 16 (1987) p.159.

[25] H.A. Wriedt and L. Zwell, T. Metall. Soc. AIME 224 (1962) p.1242.

[26] P. Ferguson and K.H. Jack, Heat Treatement '81, the Metals Society, London, 1983, p.158

[27] A. Leineweber, H.Jacobs, F.Hüning, H. Lueken and W. Kockelmann, J. Alloys Compd. 316 (2001) p.21.

[28] Topas, General Profile and Structure Analysis Software for Powder Diffraction Data, V2.0 (Bruker AXS GmbH, Karlsruhe, Germany).

[29] R.W. Cheary, A. Coelho and J.P. Cline, J. Res. NIST 109 (2004) p.1.

[30] G.K. Williamson and W.H. Hall, Acta Metall. 1 (1953) p.22.

[31] R. Delhez, Th.H. de Keijser and E.J. Mittemeijer, Fresen. Z. Anal. Chem. 312 (1982) p.1.

[32] P. Rochegude and J. Foct, Phys. Status Solidi A 88 (1985) p.137.

[33] B. Palosz, E. Grzanka, S. Gierlotka, S. Stel'makh, R. Pielaszek, W. Lojkowski, U. Nismayer, J. Neuefeind, H.-P. Weber and W. Palosz, Phase Transit. 76 (2003) p.171.

[34] P. Rochegude and J. Foct, Phys. Status Solidi A 98 (1986) p.51.

[35] J. Foct, Mater. Sci. Forum 325-326 (2000) p.99.

[36] J. Eckert, J. C. Holzer, C. E. Krill and W. L. Johnson, J. Mater. Res. 7 (1992) p.1751.

[37] W. Köster and W. Horn, Arch. Eisenhüttenwesen 37 (1966) p.155.

[38] M.A.J. Somers, R.M. Lankreijer and E.J. Mittemeijer, Phil. Mag. A 59 (1989) p.353.

[39] C.C. Koch and J. Narayan, Mater. Res. Soc. Symp. 634 (2001) B5.1.1. 
[40] I.A. Ovid'ko, Int. Mater. Rev. 50 (2005) p.65.

[41] Y. Ivanisenko, I. MacLaren, R.Z. Valiev and H.-J. Fecht, Adv. Eng. Mater. 7 (2005) p.1011.

[42] Y. Ivanisenko, W. Lojkowski, R.Z. Valiev and H.-J. Fecht, Acta Mater. 51 (2003) p.5555.

[43] A. Latapie and D. Farkas, Model. Simul. Mater. Sci. Eng. 11 (2003) p.745.

[44] B.E. Warren, Progr. Met. Phys. 8 (1959) p.147.

[45] C.N.J. Wagner, A.S. Tetelman and H.M. Otte, J. Appl. Phys. 33 (1962) p.3080.

[46] M. Chen, E. Ma, K.J. Hemker, H. Sheng, Y. Wang and X. Cheng, Science 300 (2003) p.1275.

[47] X.Z. Liao, F. Zhou, E.J. Lavernia, S.G. Srinivasan, M.I. Baskes, D.W. He and Y.T. Zhu, Appl. Phys. Lett. 83 (2003) p.632.

[48] X.L. Wu, X.Z. Liao, S.G. Srinivasan, F.Zhou, E.J. Lavernia, R.Z. Valiev and Y.T. Zhu, Phys. Rev. Lett. 100 (2008) 095701 
Table 1: Nitrogen and oxygen content of starting materials

\begin{tabular}{ccc}
\hline & nitrogen content $($ at $\%)$ & oxygen content $($ at $\%)$ \\
\hline$\alpha-\mathrm{Fe}$ & $0.04 \pm 0.01$ & $1.1 \pm 0.03$ \\
\hline$\varepsilon-\mathrm{Fe}_{3} \mathrm{~N}_{1.08}$ & $26.7 \pm 0.8$ & $1.3 \pm 0.1$ \\
\hline
\end{tabular}

Table 2: Initial nitrogen content of powder mixtures before milling and final nitrogen and oxygen contents of powders in as-milled state (milling time $40 \mathrm{~h}$ ). The number between brackets in the column "initial composition" indicates the $\varepsilon$-nitride/ferrite weight ratio in the initial powder mixture.

\begin{tabular}{cccc}
\hline samples & initial composition & \multicolumn{2}{c}{ as-milled } \\
\hline & $\begin{array}{c}\text { N content (at\%) } \\
(\varepsilon \text {-nitride /ferrite } \\
\text { weight ratio })\end{array}$ & N content (at\%) & oxygen content (at\%) \\
\hline A1 & $0(0)$ & $0.66 \pm 0.02$ & $1.4 \pm 0.03$ \\
\hline A2 & $3.4(0.14: 1)$ & $4.4 \pm 0.1$ & $2.9 \pm 0.1$ \\
\hline A3 & $6.0(0.25: 1)$ & $7.1 \pm 0.1$ & $2.1 \pm 0.04$ \\
\hline A4 & $11.1(0.59: 1)$ & $10.7 \pm 0.2$ & $4.7 \pm 0.08$ \\
\hline A5 & $11.1(0.59: 1)$ & $11.8 \pm 0.8$ & $2.8 \pm 0.40$ \\
\hline A6 & $14.7(1: 1)$ & $15.6 \pm 0.2$ & $3.0 \pm 0.1$ \\
\hline
\end{tabular}

Table 3: Results of evaluating of Mössbauer spectra recorded from sample A5: relative abundance $P_{i}$ (for comparison: values for a binomial distribution of nitrogen as calculated for the given sample composition (11.8 at $\% \mathrm{~N}$ ) have been given in brackets) and the peak width.

\begin{tabular}{cccc}
\hline Fe & hyperfine field domain & relative abundance & peak's width \\
environment & $\Delta_{\mathrm{i}}(\mathrm{T})$ & $\begin{array}{c}\text { [binomial distribution] } \\
(\mathrm{mm} / \mathrm{s})\end{array}$ \\
& & $P_{\mathrm{i}}(\%)$ & \\
\hline $\mathrm{Fe}_{0}$ & $32-36$ & $56 \pm 2[48.6]$ & $\sim 0.33$ \\
\hline $\mathrm{Fe}_{1}$ & $27-31$ & $23.5 \pm 1[35.8]$ & $\sim 0.38$
\end{tabular}




\begin{tabular}{cccc}
\hline $\mathrm{Fe}_{2}$ & $23-26$ & $18 \pm 1[12.4]$ & $\sim 0.58$ \\
\hline $\mathrm{Fe}_{\mathrm{n}}$ & 0 & $2.5 \pm 0.5$ & $\sim 0.63$ \\
\hline
\end{tabular}

Table 4: FHWM values, as obtained from the refinement procedure on the basis of an assumed tetragonal distortion of the bcc-unit cell, for the different sub-reflections resulting from splitting up the bcc-reflections

\begin{tabular}{cccc}
\hline \multirow{2}{*}{$h l_{b c c}$} & $h k l_{b c t}$ & $\begin{array}{c}\text { Relative intensity } \\
\text { of sub-reflection }\end{array}$ & FHWM [02 $\theta]$ \\
\hline \multirow{2}{*}{110} & 110 & 1 & 1.69 \\
\cline { 2 - 4 } & $101+011$ & 2 & 2.45 \\
\hline \multirow{2}{*}{200} & $200+020$ & 2 & 4.19 \\
\cline { 2 - 4 } & 002 & 1 & 9.16 \\
\hline \multirow{2}{*}{211} & $211+121$ & 2 & 5.00 \\
\hline \multirow{2}{*}{220} & 112 & 1 & 30.9 \\
\hline & 220 & 1 & 6.45 \\
\hline
\end{tabular}

Table 5: Values of $J^{\prime}{ }_{h l}$ for bcc-powder reflections $h k l$ as used in Eq. (6) and (8) [44]

\begin{tabular}{cccccccc}
\hline$h k l$ & 110 & 200 & 211 & 220 & 310 & 222 & 321 \\
\hline$J^{\prime}{ }_{h k l}$ & +0.208 & -0.167 & +0.021 & +0.208 & -0.167 & -0.167 & +0.048 \\
\hline
\end{tabular}




\section{FIGURES}

Fig. 1: X-ray powder diffraction patterns (Mo-K $\alpha_{1}$ radiation, $\left.\lambda=0.70926 \AA\right)$ of the initial mixture of $\alpha$-iron powder and $\varepsilon-\mathrm{Fe}_{3} \mathrm{~N}_{1.08}$ powder (weight ratio $1.72: 1$ ) and as after various milling times. With increasing milling time, all reflections become substantially broadened. Further, the $\varepsilon$-nitride reflections disappear: the ball-milled material can be indexed as of single-phase bcc structure. After $40 \mathrm{~h}$ of milling a stationary state is reached with respect to the line broadening and the phase composition. Diffraction patterns have been shifted along the ordinate to facilitate their comparison.

Fig. 2: Comparison of diffraction patterns (Mo-K $\alpha_{1}$ radiation, $\lambda=0.70926 \AA$ ) of (a) a mixture of $\alpha$-iron powder and $\varepsilon$-iron nitride powder (weight ratio $1.5: 1$ ), where each powder was ball milled separately for $40 \mathrm{~h}$ and (b) a mixture of $\alpha$-iron powder and $\varepsilon$-iron nitride powder (weight ratio 1.5:1) ball milled after mixing, i.e. together, for 40 hours (sample A5, identical with the diffraction pattern at the bottom of Fig. 1). Whereas in pattern (a) the reflections of the $\varepsilon$ nitride are still discernable despite of some broadening, they are no longer detectable in pattern (b), where furthermore the reflections of the ferrite are much more broadened then in (a). This demonstrates that in case of milling of $\alpha$-iron and $\varepsilon$-iron nitride powders together, an alloying process has occurred.

Fig. 3: X-ray powder diffraction patterns (Co-K $\alpha$ radiation, $\left.\lambda_{\alpha 1}=1.78897 \AA, \lambda_{\alpha 2}=1.79258 \AA\right)$ of the milling products after 40 hours of milling (stationary states). Due to different initial weight ratios of $\alpha$-iron powder and $\varepsilon$-iron nitride powder, the mixed powders have different total nitrogen contents. 
Fig. 4: Williamson-Hall plots for the diffraction patterns of the supersaturated N-ferrites (cf. Fig. 3). Only the 110, 211 and 220 reflections were used for the linear fit, because the 200 reflections are very weak and exhibit very pronounced broadening, rendering determination of their line-broadening parameters unreliable.

Fig. 5: Reciprocal average crystallite size (a) and average microstain (b), as determined from the Williamson-Hall plots (Fig. 4), versus nitrogen content. The error bars indicate the standard deviations of the ordinate intercepts and slopes, respectively, corresponding to the straight lines drawn in the Williamson-Hall plots.

Fig. 6: (a) Apparent bcc-lattice parameters as determined from the position of the individual reflections of the supersaturated N-ferrites of various nitrogen contents. (b) Apparent bcclattice parameters are determined by fitting of Eq. (4), to the experimental data shown in (a) for the reflections' maxima.

Fig. 7: (a) Mössbauer spectrum taken from sample A5 (11.7 at $\% \mathrm{~N})$; the black solid line represents the best fit employing 7 sets of 6 peaks corresponding to 7 different magnetic states of iron atoms (represented by dotted lines), with an additional single peak close to $0 \mathrm{~mm} / \mathrm{s}$ (represented by the dashed line). (b) Mössbauer spectrum of virginal $\alpha^{\prime}-\mathrm{FeN}_{0.09}(8.2 \mathrm{at} \% \mathrm{~N}$; nitrogen martensite) produced by quenching from the austenite-phase field, containing residual austenite [33]. 
Fig. 8: SAD pattern (a) and high resolution image (b) of sample A1 (pure iron) after 40 hours of ball milling; SAD pattern (c) and high resolution image (d) of sample A4 (10.7 at $\% \mathrm{~N})$ after 40 hours of ball milling.

Fig. 9: High resolution electron microscopy image of sample A4 (10.7 at $\% \mathrm{~N})$ after $40 \mathrm{~h}$ of ball milling. Two neighbouring bcc crystallites (bcc1 and bcc2) exhibit the orientation relationship $\{1 \overline{1} 0\}_{\text {bcc1 }} \|\{110\}_{\text {bcc } 2}$ and $<111>_{\text {bcc1 }} \|<001>_{\text {bcc2 }}$. Furthermore, a crystallite of fcc structure is visible. For each of these three crystallites, a local fast Fourier transformation (FFT) of the image has been made to identify the crystal structure and the corresponding zone axis parallel to the incident electron beam.

Fig. 10: Result of diffraction-profile fitting (upper grey line), on the basis of the tetragonal distortion model of the bcc-unit cell, to the measured diffraction pattern of a supersaturated Nferrite (sample A4, 10.7 at $\%$ N). Bottom grey line: difference curve.

Fig. 11: Values for the true lattice parameter $a_{0}$ and the product of stacking fault probability, $\alpha$ (left ordinate), and increase in lattice plane spacing at the stacking faults, $\varepsilon$ (right ordinate), as deduced from fitting of the stacking-fault model, (Eq. (4)), to the experimental data for the reflections' maxima.

Fig. 12: Schematic representation of a stacking fault on a (211)-plane in iron in a [1 $\overline{1} 0]$ projection. The light grey atoms have been shifted by $0.5 \cdot[1 \overline{1} 0]$, i.e. perpendicular to the plane of drawing, with respect to the dark grey atoms. The plane of faulting is represented by the horizontal dashed line. An octahedral site in the undisturbed lattice (bulk) and an 
octahedral site at the stacking fault are displayed by the solid lines. The anisotropy of the octahedral site in the perfect bcc-lattice is clearly visible (two nearest Fe neighbours in $<001>$-direction), whereas the octahedral site at the stacking fault is more regular, especially when atomic relaxation by atomic shuffling takes place as indicated by the arrows and the dotted circles. 


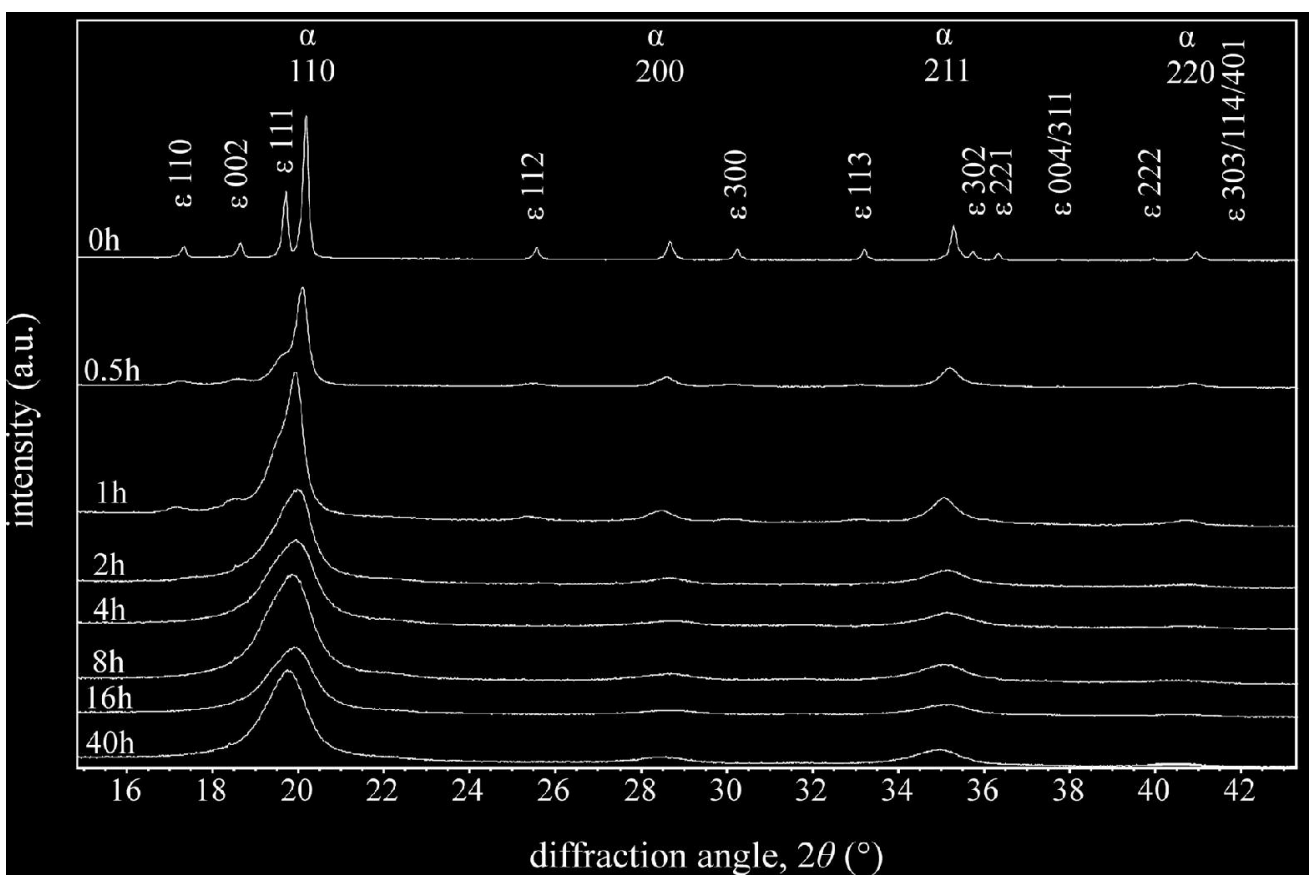

Figure 1

$79 \times 52 \mathrm{~mm}(600 \times 600 \mathrm{DPI})$ 


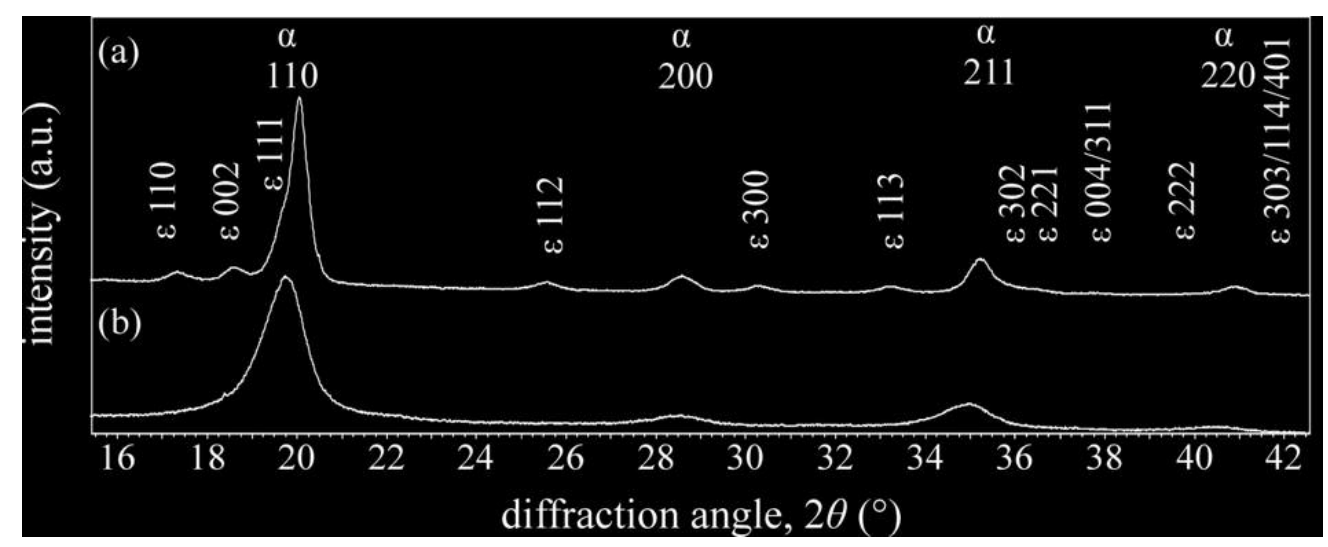

Figure 2

$40 \times 16 \mathrm{~mm}(600 \times 600$ DPI $)$ 


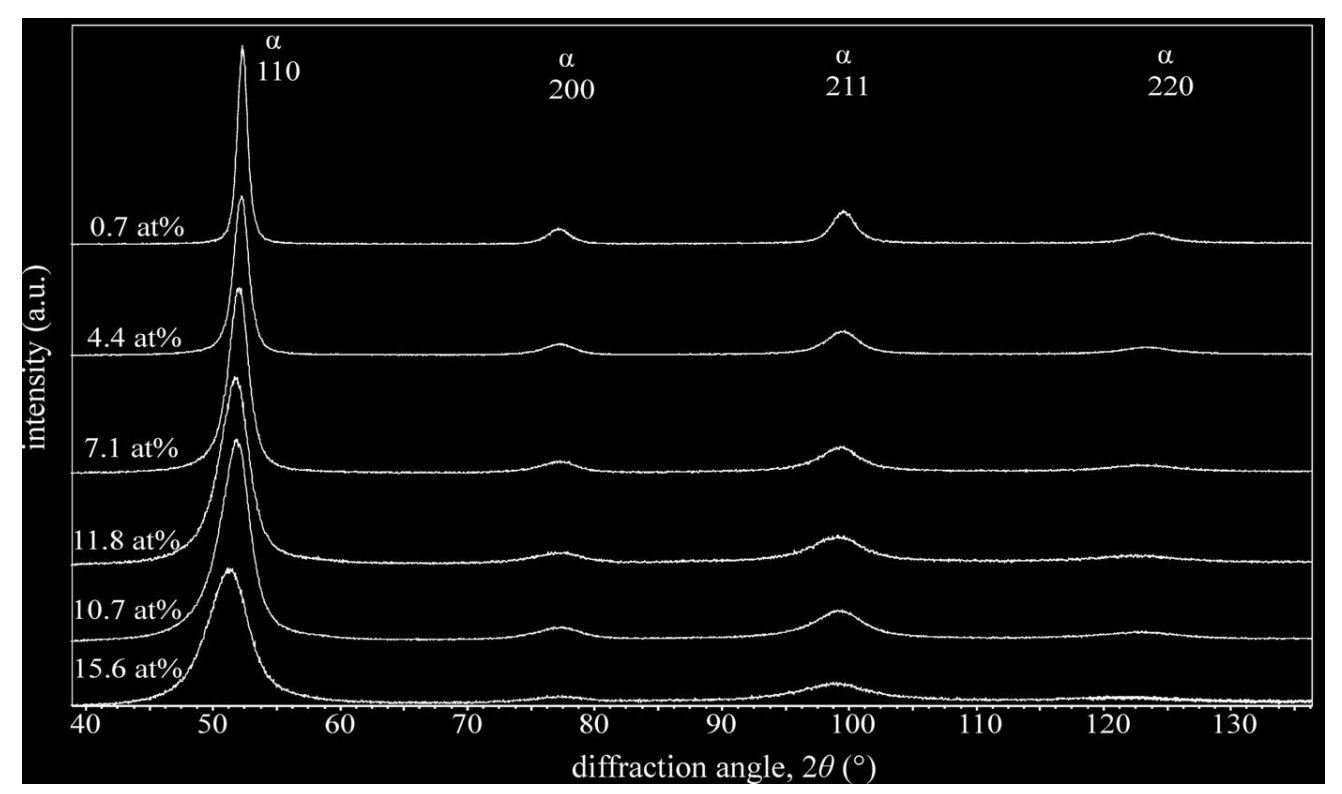

Figure 3

$58 \times 34 \mathrm{~mm}(600 \times 600 \mathrm{DPI})$ 


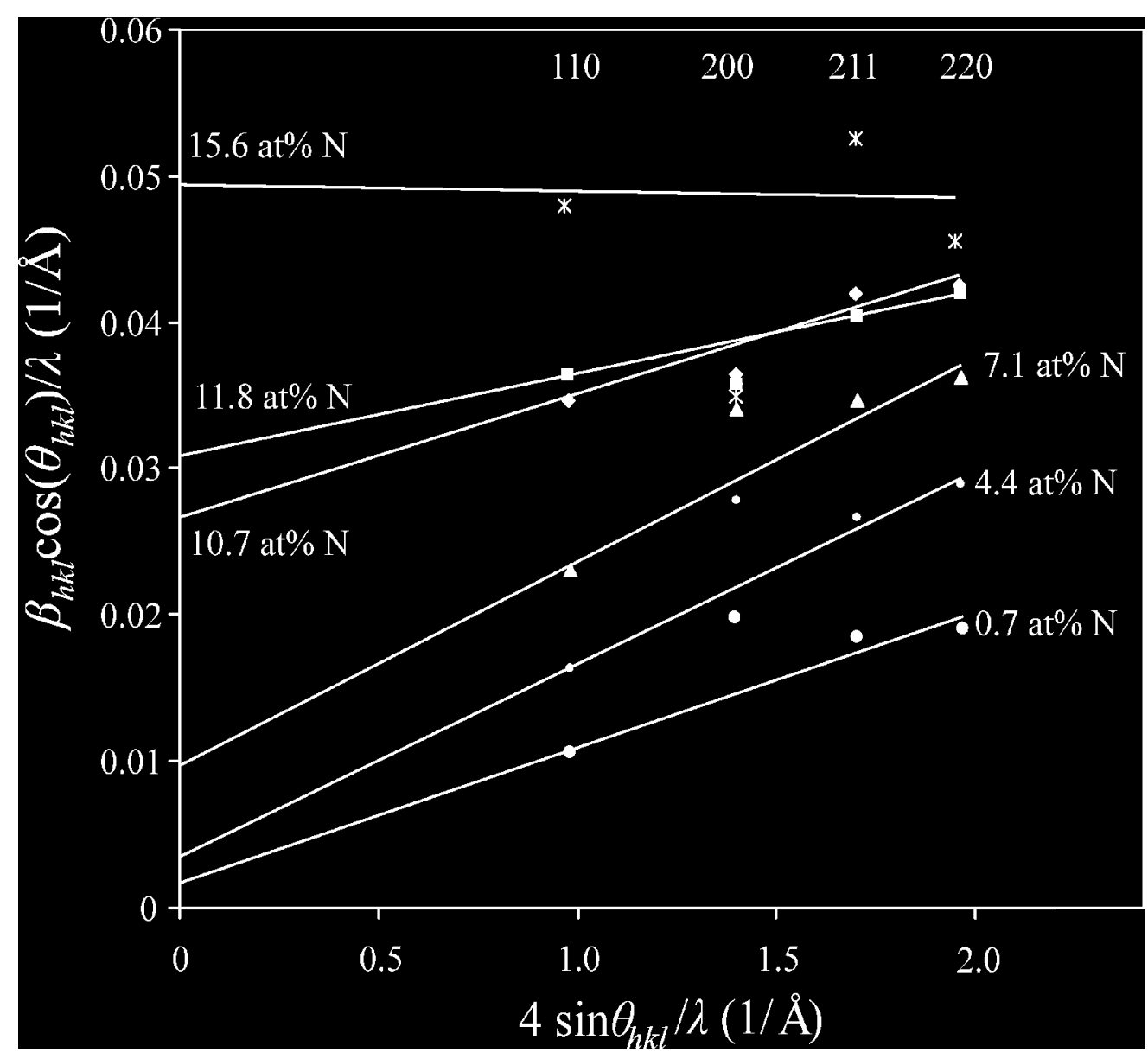

$148 \times 136 \mathrm{~mm}(600 \times 600 \mathrm{DPI})$ 


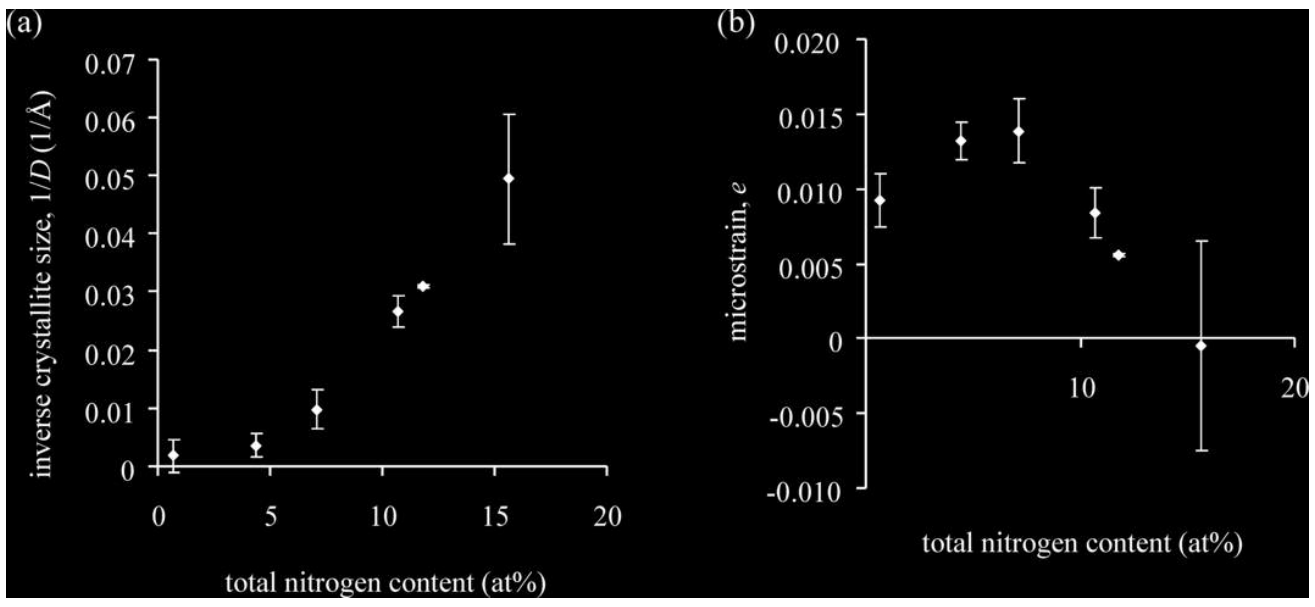

Figure 5

$45 \times 20 \mathrm{~mm}(600 \times 600 \mathrm{DPI})$ 

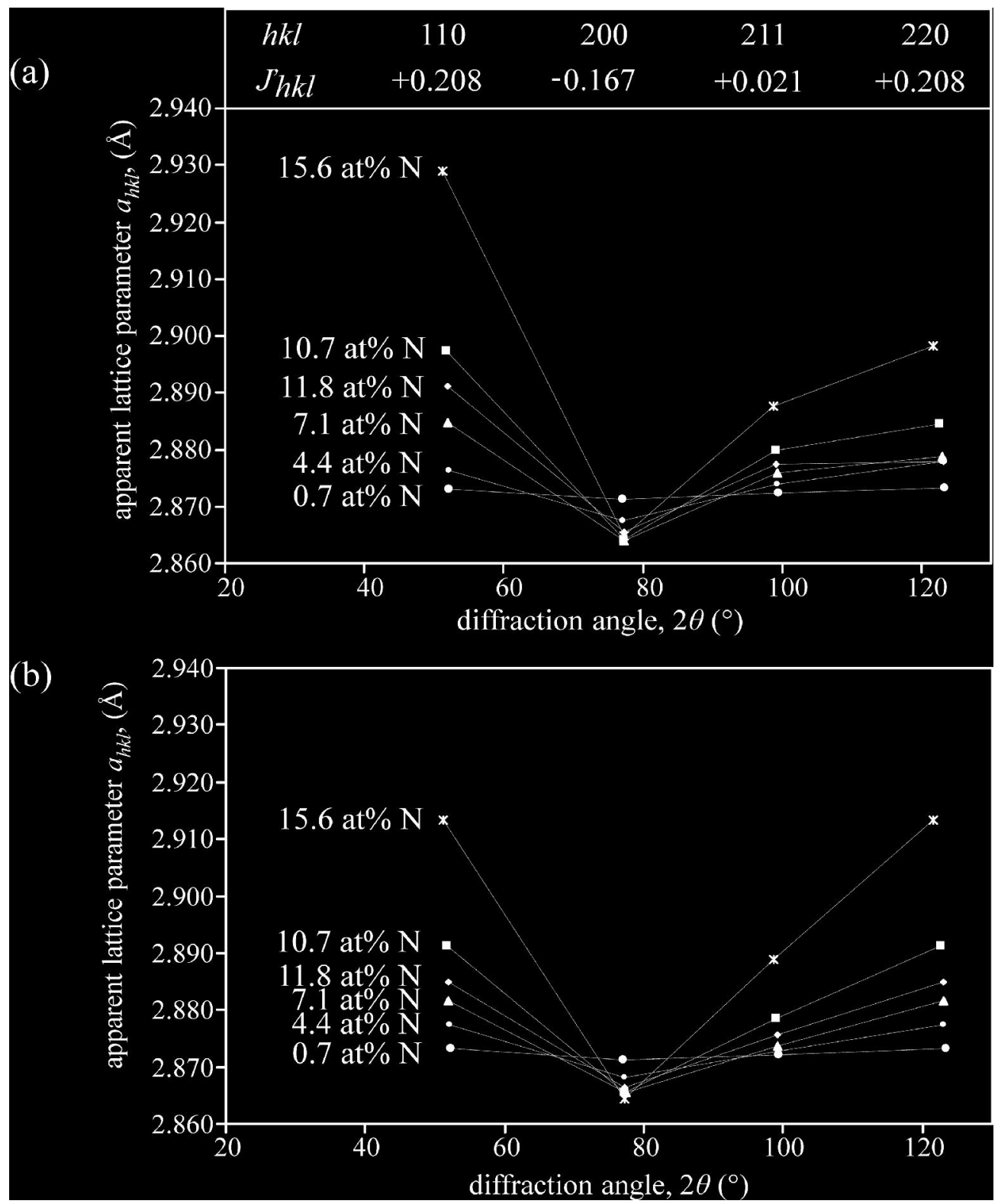

Figure 6

$121 \times 146 \mathrm{~mm}(600 \times 600 \mathrm{DPI})$ 


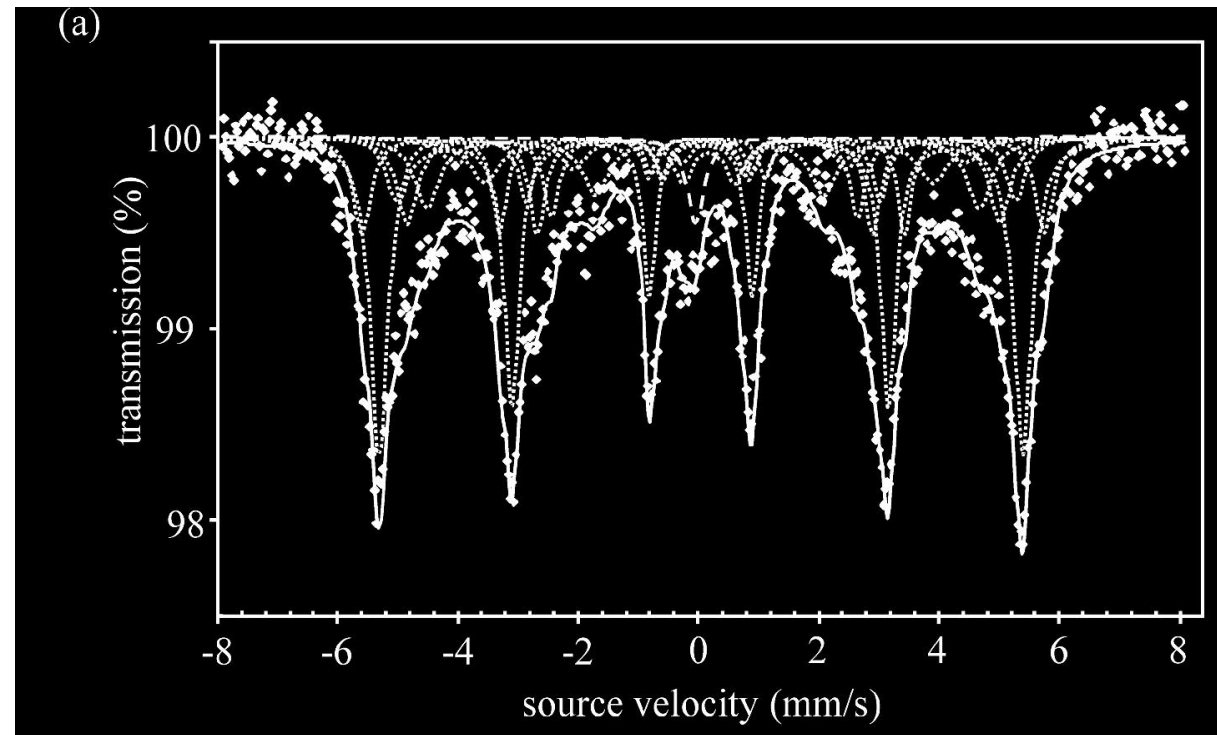

(b)

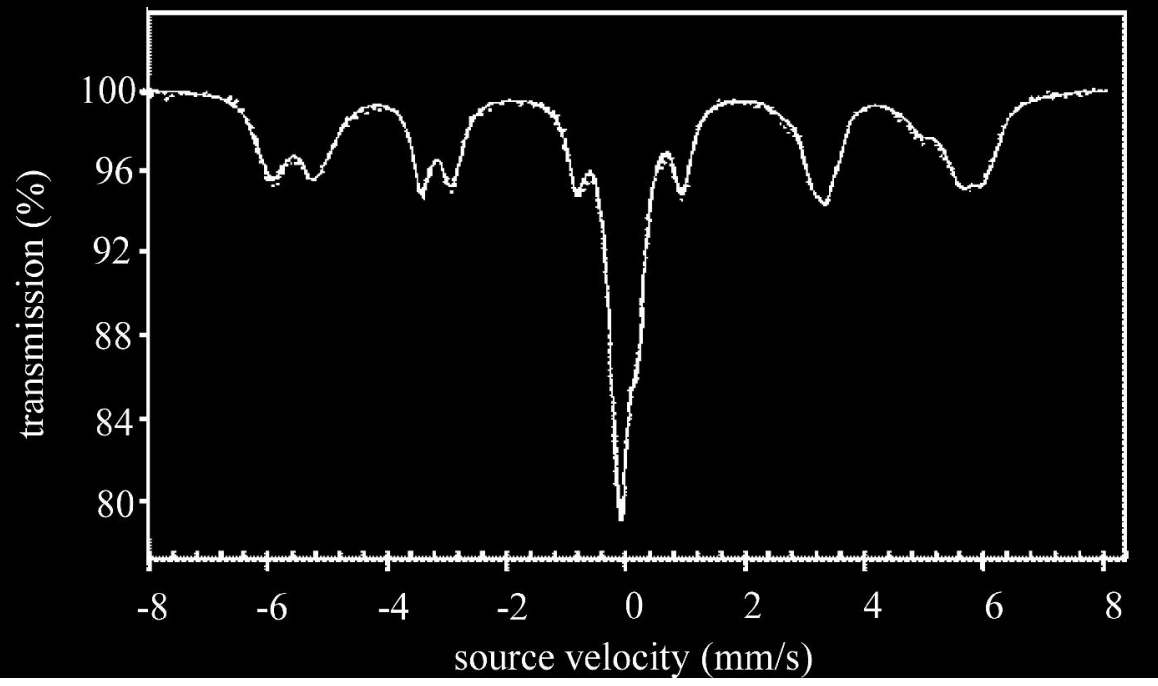

Figure 7

$127 \times 161 \mathrm{~mm}(600 \times 600 \mathrm{DPI})$ 
(a)

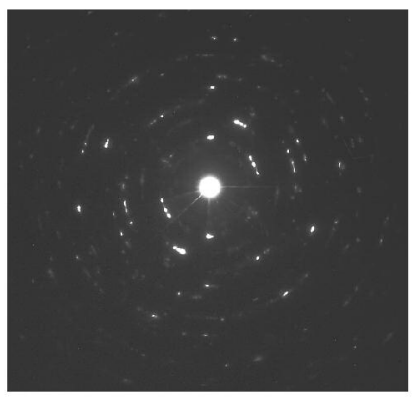

(c)

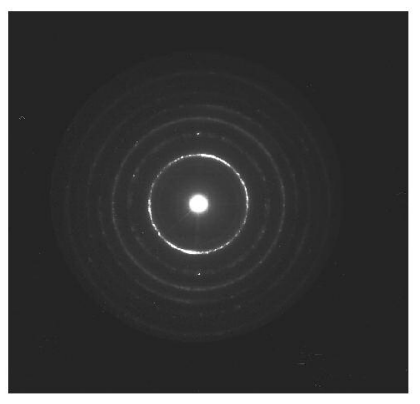

(b)

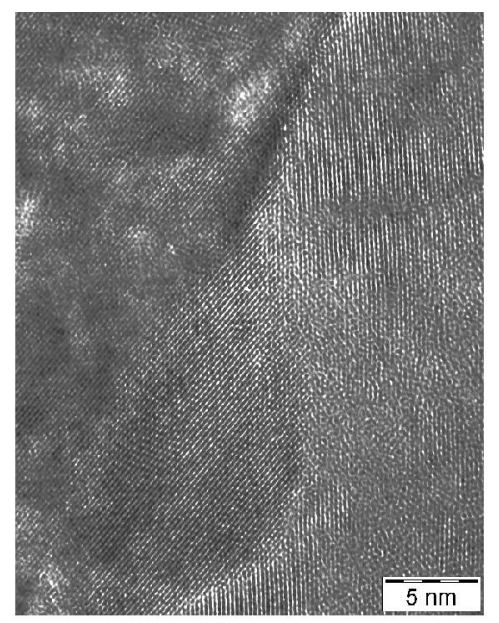

(d)

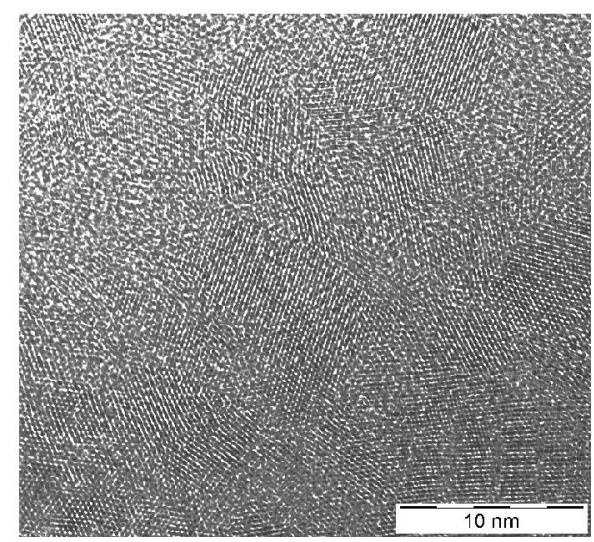

Figure 8

$99 \times 88 \mathrm{~mm}(450 \times 450 \mathrm{DPI})$ 


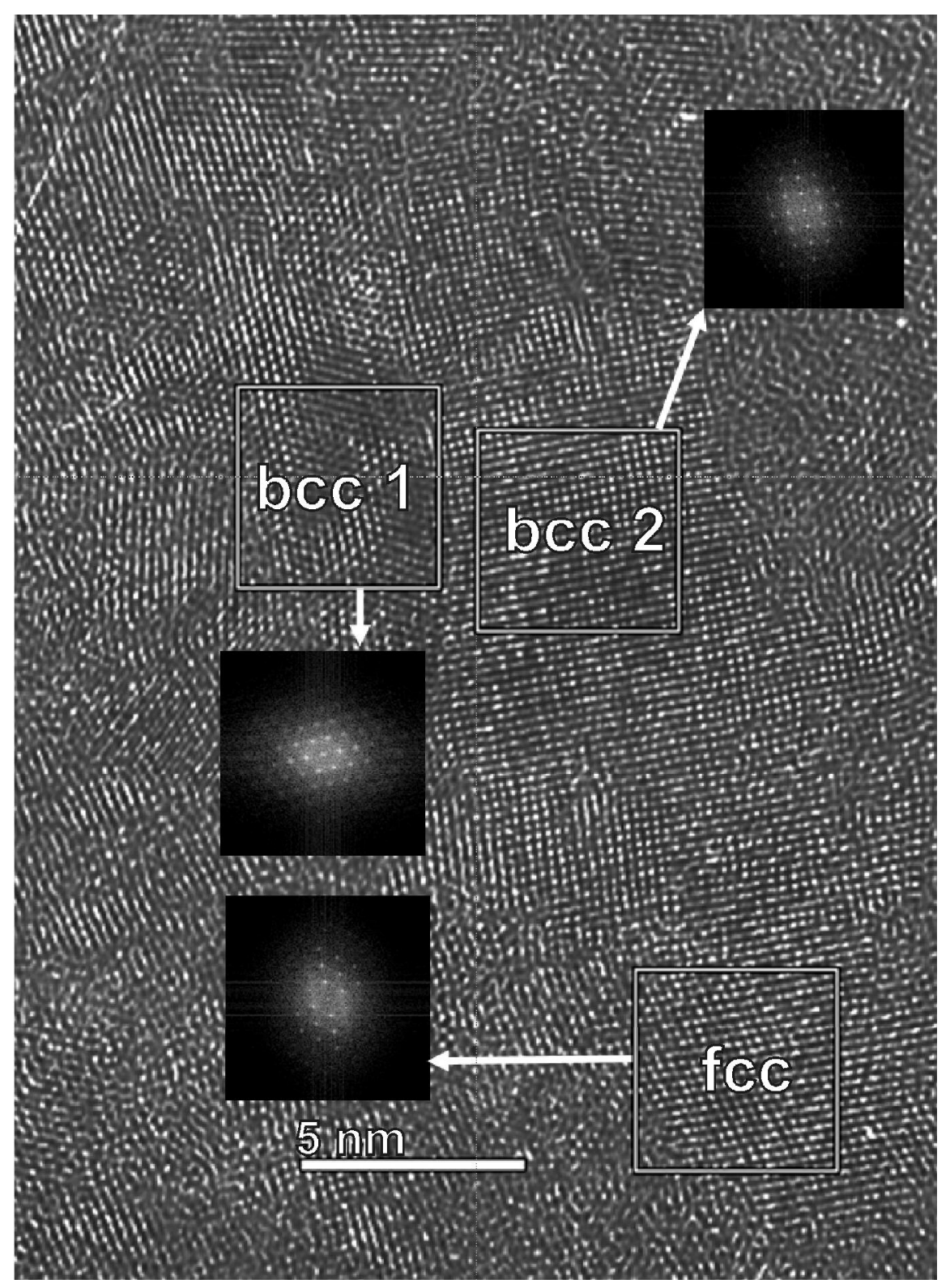

Figure 9

$99 \times 136 \mathrm{~mm}(450 \times 450 \mathrm{DPI})$ 


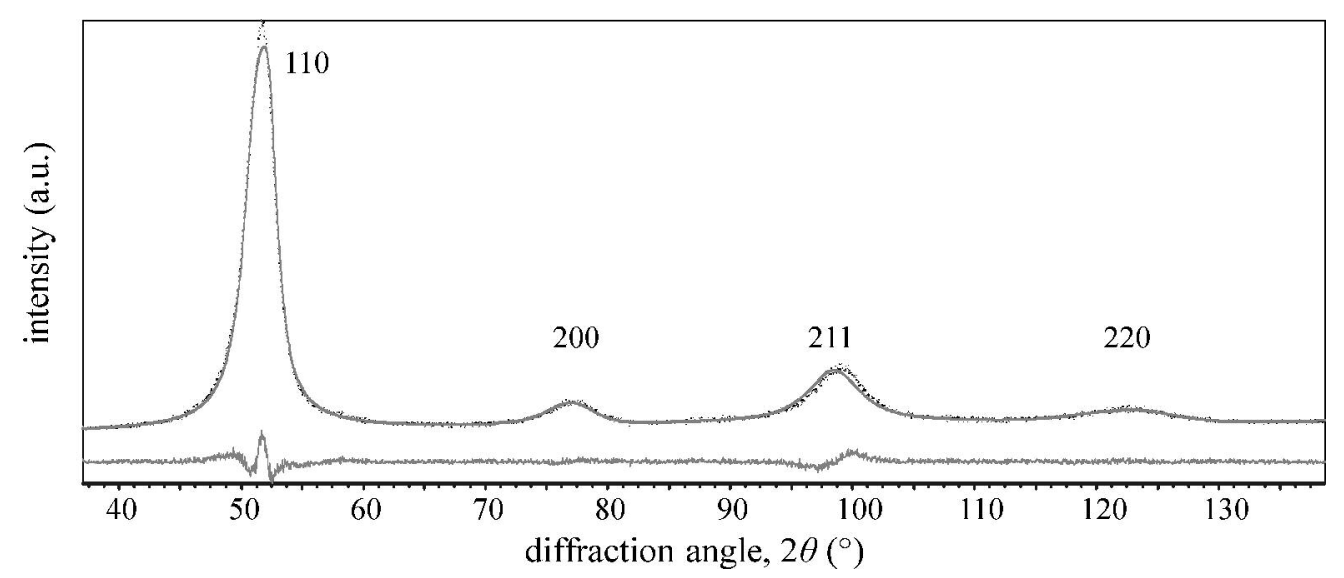

$132 \times 56 \mathrm{~mm}(600 \times 600 \mathrm{DPI})$ 


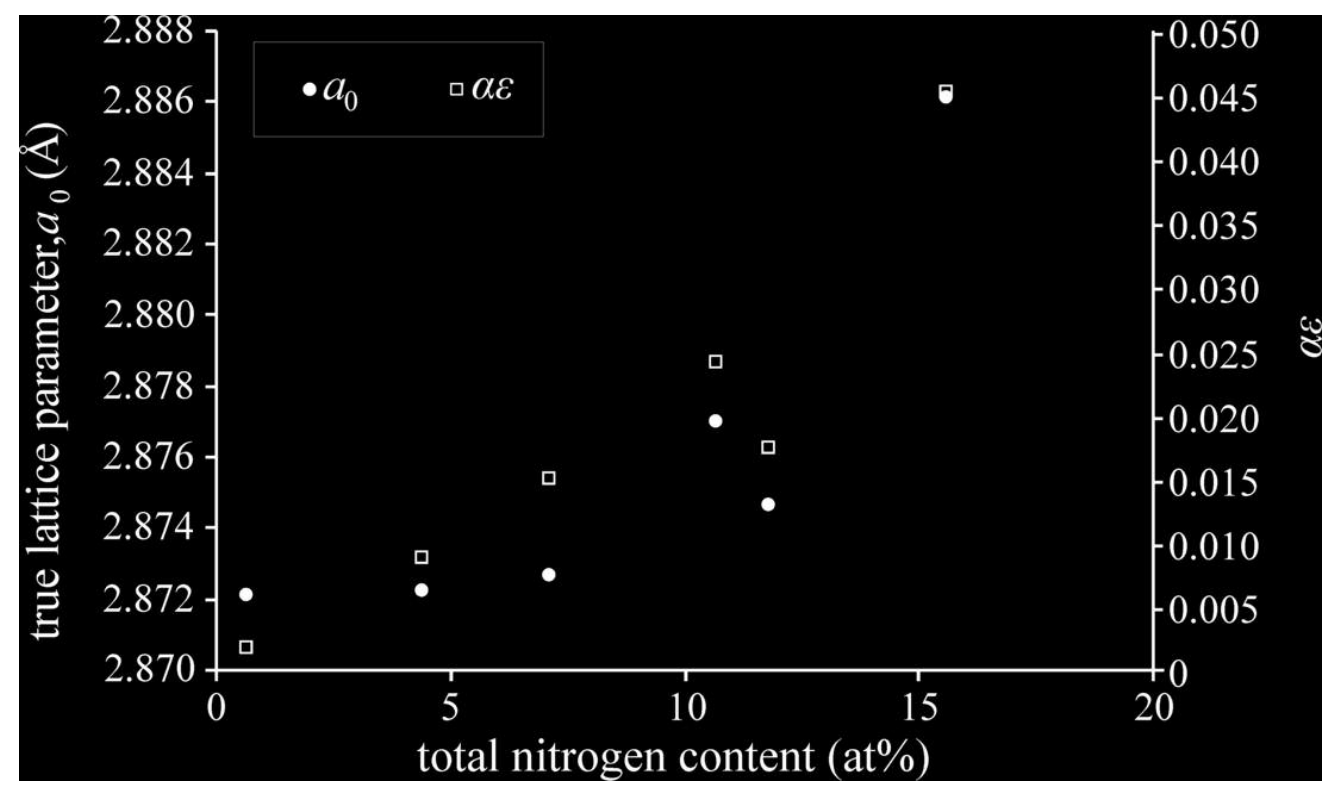

$46 \times 27 \mathrm{~mm}(600 \times 600 \mathrm{DPI})$ 


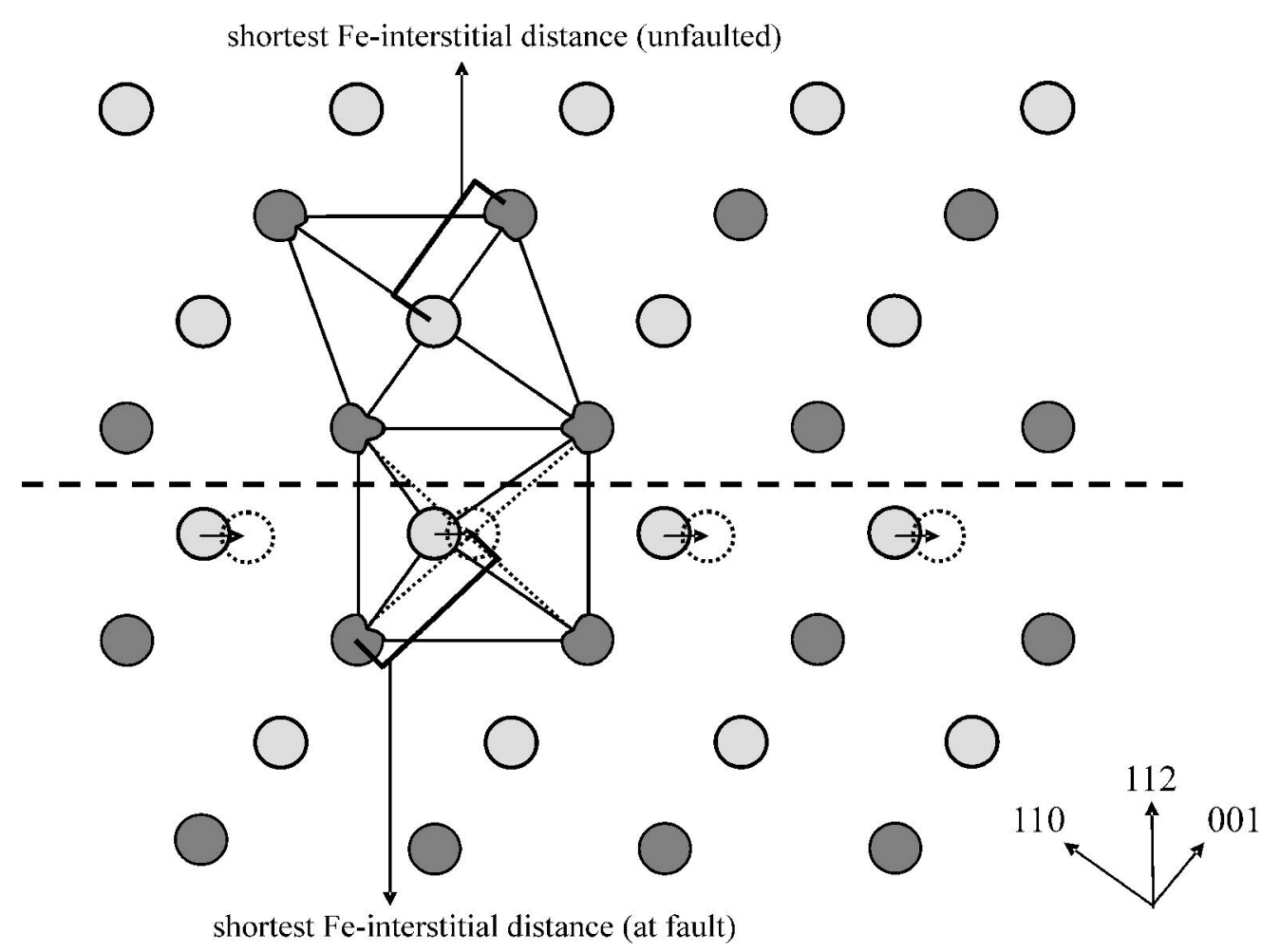

Figure 12

$194 \times 145 \mathrm{~mm}(600 \times 600$ DPI $)$ 